\title{
Research on Stability Prediction of the Crankshaft CNC Tangential Point Tracing Grinding
}

\author{
Zhuoda Jiang ${ }^{1,2}$ and Yongyi He ${ }^{1}$ \\ ${ }^{1}$ Shanghai Key Laboratory of Intelligent Manufacturing and Robotics, School of Mechatronic Engineering and Automation, \\ Shanghai University, No. 149 Yanchang Road, Mailbox 232, Shanghai 200072, China \\ ${ }^{2}$ Jiangxi Key Laboratory of Numerical Control, Jiujiang University, Jiujiang, Jiangxi 332005, China
}

Correspondence should be addressed to Zhuoda Jiang; jzd000@163.com

Received 16 June 2015; Revised 31 August 2015; Accepted 6 September 2015

Academic Editor: Ivanka Stamova

Copyright (C) 2015 Z. Jiang and Y. He. This is an open access article distributed under the Creative Commons Attribution License, which permits unrestricted use, distribution, and reproduction in any medium, provided the original work is properly cited.

\begin{abstract}
As the key part of internal combustion engines, crankshaft with high efficiency and accuracy processing has always been the target of the engine manufacturer's pursuit. Grinding is used to obtain the ultimate dimensional accuracy and surface finish in the crankshaft machining. Grinding of the main journals and the pin journals can be accomplished in a single clamping operation by CNC Tangential Point Tracing grinding technology. However, the chatter in the grinding process is harmful to the precision and surface quality. In this paper, stability lobe diagram is developed to predict the grinding chatter. First the dynamic model of Tangential Point Tracing grinding system is established. Then the limit formula of the critical grinding depth is calculated and the stability lobe diagram of the grinding system is presented. Finally, the validation experiments are carried out on the crankshaft grinding machine and the results are consistent with the calculation.
\end{abstract}

\section{Introduction}

Crankshaft is one of the key components of engines in automotive industry and its rotation is the power source of the engine. It consists of two important parts: the crankshaft main journal and crankpin. The crankshaft main journal is mounted on the cylinder, while the crankpin is connected to the big end hole of the connecting rod and its other end hole is connected to the cylinder piston. It is a typical slider crank mechanism and it turns the reciprocating motion of the connecting rod into rotating motion. The quality of crankshaft determines the performance of the engine. The crankshaft of an engine is shown in Figure 1.

The traditional crankshaft grinding process of main journal is similar to the cylindrical grinding. The crankpin is adjusted to the center of the grinding by the eccentric fixture and each crankshaft needs special fixture. It has long auxiliary hours and low processing precision when the clamp is adjusting by the operator [1].

Nowadays, the crankshaft is mechanized by the method of CNC Tangential Point Tracing grinding. Grinding of the main journals and the pin journals can be accomplished in a single clamping operation. The grinding method can avoid the positioning error caused by multiple loadings and save the adjustment time. High machining flexibility, accuracy, and efficiency are also improved. CNC Tangential Point Tracing Grinding Crankshaft is high technology processing and it was called Oscillate grinding [2] or Chasing the pin [3] by some scholars. Tangential Point Tracing grinding mode is composed of linkage between the workpiece rotation ( $C$ axis) and reciprocating motion of the grinding wheel ( $x$ axis) to achieve the eccentric circle machining.

The chatter in the grinding process can result in increased tolerance of dimension and position, the surface roughness and waviness, which seriously affect dimensional accuracy and surface finish of the crankshaft. The chatter in the machining is usually accompanied by considerable noise [4].

There are lots of measures that can effectively control chatter such as using the drive to improve the dynamic stiffness and damping of the grinding machine system to reduce the regenerative phase [5], but these methods need to change the structure of machine tools and they are not suitable for the users. 


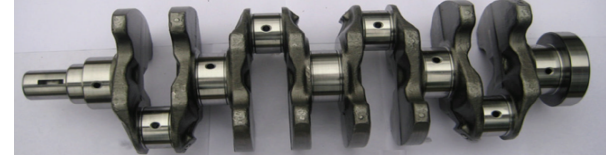

FIgURE 1: Crankshaft.

The stability of the stable region and the unstable region can be visually described by the stability lobe diagram $[6,7]$. In order to avoid the grinding chatter, the Tangential Point Tracing grinding was set as the research object. The stability lobe chart was used to visually describe the grinding stability region and the unstable region. To predict the grinding stability, the machining quality and the machining efficiency of the grinding process are ensured [8].

\section{The Tangential Point Tracing Grinding}

With increased demands of industry, Tangential Point Tracing grinding process has been developed to machine nonround shaped parts such as crankshaft and camshaft allowing reduction of nonproductive time and reclamping inaccuracies [9].

The grinding point moves along the surface of the crankpin, while the grinding wheel is always tangent to the crankpin in the grinding process. Figure 2 illustrates the concept of Tangential Point Tracing grinding [3]. The crankpin rotates around the $C$ axis followed by horizontal movement of the wheel head along the $x$ axis. All of the main journals and crankpins of a concentrically clamped crankshaft can be machined in one fixture that improves the efficiency and accuracy of the products.

Figure 3 is the schematic of Tangential Point Tracing grinding motion model. The crankpin is rotated around the $O$ point, and the wheel is followed by the movement. The trajectory equation of the tangent points coordinates can be expressed as follows:

$$
\begin{array}{r}
x=R \cos \alpha+R_{W} \cos \beta \\
y=R \sin \alpha-R_{W} \sin \beta \\
R \sin \alpha=\left(R_{S}+R_{W}\right) \sin \beta .
\end{array}
$$

In Figure 3, $O$ is the crankshaft turning center. $O_{W}$ denotes the center of the crankpin. $O_{S}$ is the center of the grinding wheel.

The eccentric distance of the crankpin is $R . R_{W}$ and $R_{S}$ correspond to the radius of the crankpin and the grinding wheel, respectively.

Here, $\alpha$ and $\beta$ denote the rotation angle of the crankshaft and the angle between $\overline{\mathrm{O}_{S} \mathrm{O}_{W}}$ and $\overline{\mathrm{OO}_{S}}$.

$x$ and $y$ is describe the position of the tangent point $T$ in rectangular coordinate system, where $O$ is origin of coordinate system.

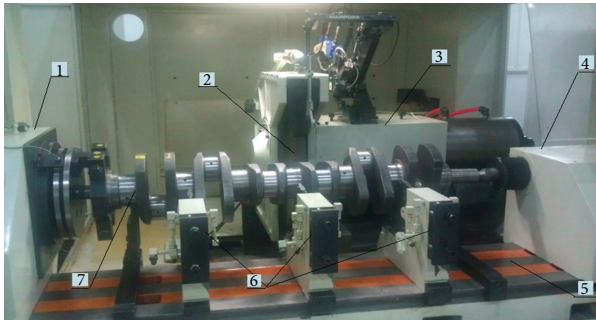

Figure 2: Tangential Point Tracing crankshaft grinding machine. 1: headstock, 2: grinding wheel, 3: wheel head, 4: tailstock, 5: worktable, 6: center rest, and 7: crankshaft.

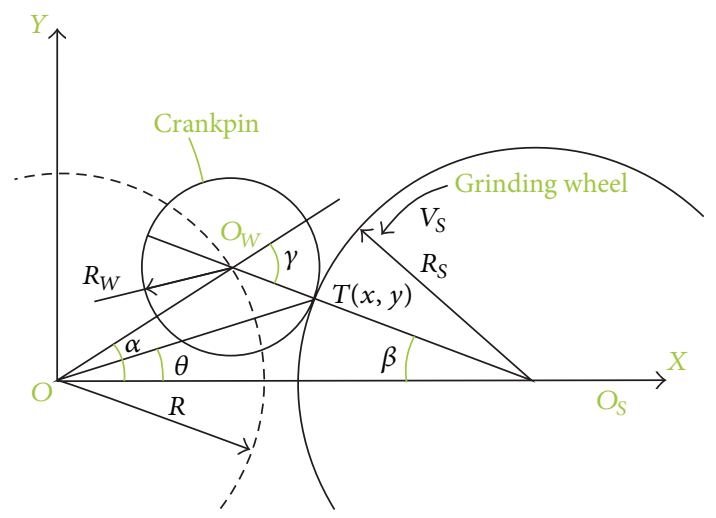

FIgure 3: Crankshaft Tangential Point Tracing grinding movement schematic diagram.

The movement equation of wheel center $O_{S}$ is as follows:

$$
X=\overline{O O_{S}}=R \cos \alpha+\left(R_{S}+R_{W}\right) \cos \beta .
$$

\section{The Dynamic Model of Tangential Point Tracing Grinding System}

3.1. Modeling and Formulation. The crankshaft is supported by the centers of the headstock and tailstock when it is machining. In order to reduce the deformation, main journals are supported by center rests. The headstock provides the low speed rotational drive to the crankshaft.

The crankpin moves around $O$ point in the XOY plane while the grinding wheel is doing a reciprocating movement in $X$ direction as shown in Figures 3 and 4(a). In this study, a simplified dynamic model of Tangential Point Tracing grinding machine and analysis are presented in Figure 4(c).

According to Newton motion law, four discrete mass dynamic equations are written as follows:

$$
\begin{aligned}
k_{2}\left(q_{3}-q_{1}\right)-c_{1} \dot{q}_{1}-k_{1} q_{1} & =m_{1} \ddot{q}_{1} \\
Q_{1}-k_{2}\left(q_{3}-q_{1}\right)-c_{3} \dot{q}_{3}-k_{3} q_{3} & =m_{2} \ddot{q}_{3} \\
k_{a}\left(-q_{2}\right)-c_{4} \dot{q}_{2}-k_{4} q_{2} & =m_{1} \ddot{q}_{2} \\
Q_{2}-k_{a}\left(-q_{2}\right) & =0
\end{aligned}
$$




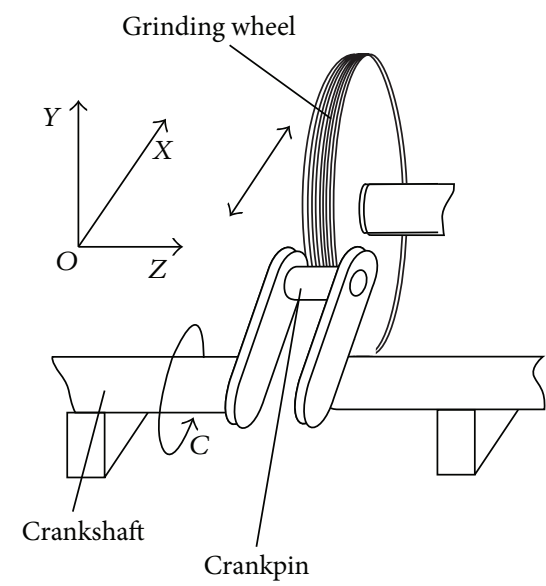

(a)

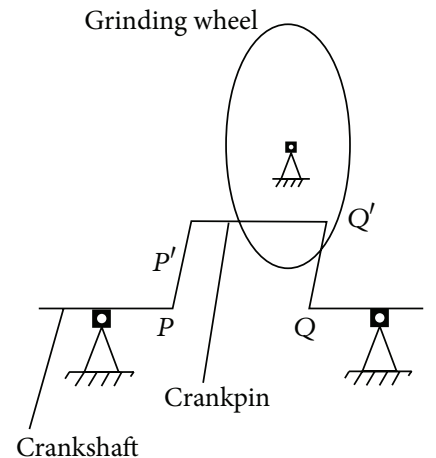

(b)

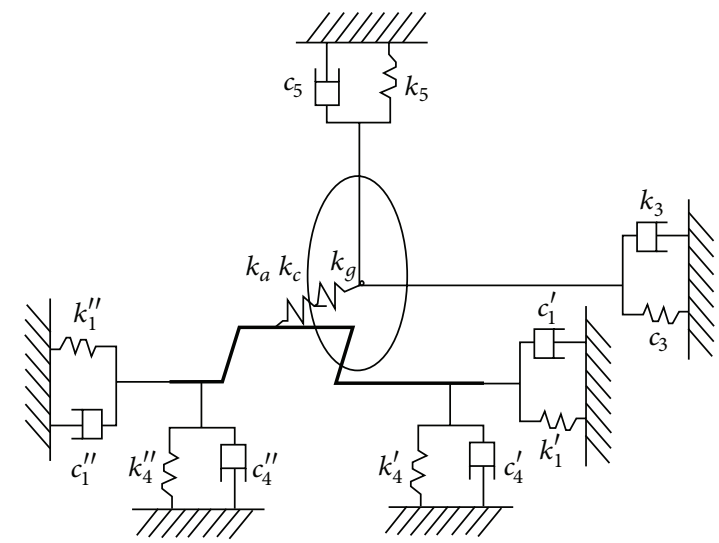

(c)

Figure 4: A simplified dynamic model of Tangential Point Tracing grinding machine.

$$
\begin{aligned}
m_{1} \ddot{q}_{1}+c_{1} \dot{q}_{1}+\left(k_{1}+k_{2}\right) q_{1}-k_{2} q_{3} & =0 \\
m_{2} \ddot{q}_{3}+c_{3} \dot{q}_{3}+\left(k_{2}+k_{3}\right) q_{3}-k_{2} q_{1} & =Q_{1} \\
m_{1} \ddot{q}_{2}+c_{4} \dot{q}_{2}+\left(k_{4}+k_{a}\right) q_{2} & =0 \\
k_{a}\left(-q_{2}\right) & =Q_{2} .
\end{aligned}
$$

For computer analysis and calculation, the upper type is changed into matrix form; the mass matrix of the system is as follows:

$$
[m]=\left[\begin{array}{cccc}
m_{1} & 0 & 0 & 0 \\
0 & m_{2} & 0 & 0 \\
0 & 0 & m_{1} & 0 \\
0 & 0 & 0 & m_{2}
\end{array}\right] .
$$

Damping matrix is

$$
[c]=\left[\begin{array}{cccc}
c_{1} & 0 & 0 & 0 \\
0 & c_{2} & 0 & 0 \\
0 & 0 & c_{3} & 0 \\
0 & 0 & 0 & c_{4}
\end{array}\right] .
$$

Stiffness matrix is

$$
[k]=\left[\begin{array}{cccc}
k_{1}+k_{2} & -k_{2} & 0 & 0 \\
-k_{2} & k_{2}+k_{3} & 0 & 0 \\
0 & 0 & k_{4}+k_{a} & -k_{a} \\
0 & 0 & -k_{a} & k_{a}+k_{5}
\end{array}\right] .
$$

The generalized coordinates and generalized forces are expressed as

$$
\begin{aligned}
\{q\} & =\left\{\begin{array}{llll}
q_{1} & q_{2} & q_{3} & 0
\end{array}\right\}^{T} \\
\{Q\} & =\left\{\begin{array}{llll}
0 & Q_{1} & 0 & Q_{2}
\end{array}\right\}^{T} .
\end{aligned}
$$

And we can express the above kinetic equation as

$$
[m]\{\ddot{q}\}+[c]\{\dot{q}\}+[k]\{q\}=\{Q\} .
$$

3.2. The Crankshaft Stiffness Is Different in the Circumferential Direction. The stiffness of the crankshaft varies not only along the axial direction, but also in the radial direction. It leads to the crankpin deformation in the circumferential direction and affects accuracy of the crankpin. In the cylindrical grinding, the direction of the normal grinding force $\left(F_{n}\right)$ and the tangential grinding force $\left(F_{t}\right)$ is invariable, but they change in the Tangential Point Tracing grinding. The grinding force is shown in Figure 5 where the angle of the crankpin is $\alpha$ :

$$
\begin{aligned}
& F_{U}=-F_{n} \times \cos \varphi-F_{t} \times \sin \varphi \\
& F_{V}=F_{n} \times \sin \varphi-F_{t} \times \cos \varphi \\
& M=-F_{t} \times R_{W} .
\end{aligned}
$$

The relationship between normal grinding force and tangential grinding force can be written as follows:

$$
F_{t}=\zeta \times F_{n} .
$$

\section{Calculation of Critical Grinding Depth}

Adjustment of the grinding process and modification of the machine tools structure are two approaches to avoid chatter. In the first approach, the stability lobe diagram that predicts the onset of chatter is used to determine the critical grinding depth and spindle speed to eliminate or minimize chatter behavior in machining [10].

It is important to study chatter mechanisms to predict critical grinding depth. We need to know grinding chatter boundaries and growth rates, which is helpful to design a grinding process without chatter according to the chatter boundaries.

In order to simplify the model of crankshaft cut into grinding system, the kinematic differential equation of the grinding wheel workpiece grinding system dynamics model is expressed as [11]

$$
m \ddot{q}(t)+c \dot{q}(t)+k q(t)= \pm F(t) .
$$




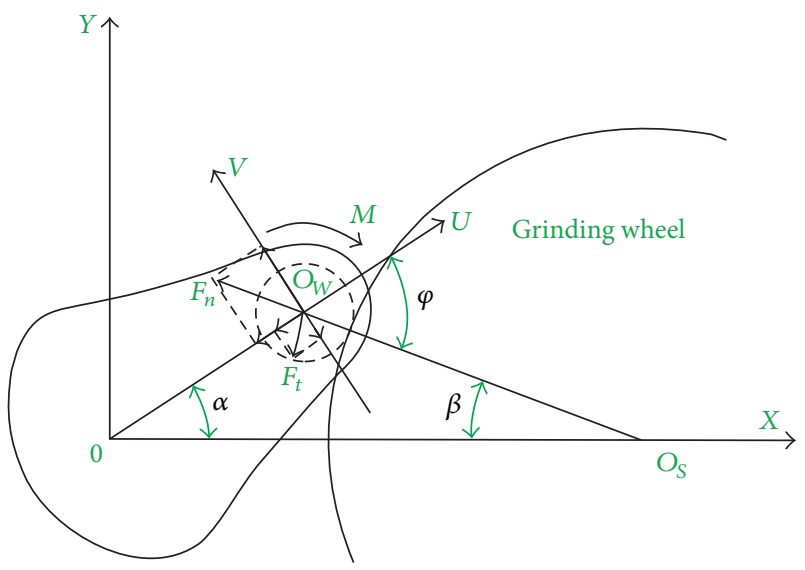

FIGURE 5: Schematic diagram of grinding force decomposition.

Dynamic grinding force is usually proportional to the removal rate of material, which has the following formula:

$$
F(t)= \pm k_{m}^{\prime} h b a(t)
$$

Among them $a(t)$ are $t$ moments of the surface of the workpiece (or wheel) surface ripple amplitude. In this model, only the delay effect from the workpiece is considered. The delay time $\tau$ is assumed to be constant and equals the workpiece's rotation period (T) [12]:

$$
a(t)=a_{0}(t)-[q(t)-q(t-T)] .
$$

And then

$$
F(t)= \pm k_{m}^{\prime} h b\left\{a_{0}(t)-[q(t)-q(t-T)]\right\} .
$$

After combining (11) and (13), we obtain the following expression:

$$
\begin{aligned}
& m \ddot{q}(t)+c \dot{q}(t)+k q(t) \\
& \quad= \pm k_{m}^{\prime} h b\left\{a_{0}(t)-[q(t)-q(t-T)]\right\} .
\end{aligned}
$$

Laplace transformations to the upper formula can be

$$
\begin{aligned}
& \left(m s^{2}+c s+k\right) q(s) \\
& \quad=k_{m}^{\prime} h b\left[a_{0}(s)-q(s)+e^{-T s} q(s)\right] .
\end{aligned}
$$

Then

$$
\begin{aligned}
& \left(m s^{2}+c s+k\right) q(s) \\
& \quad=k_{m}^{\prime} h b\left[-1+e^{-T s}\right] q(s)+k_{m}^{\prime} h b a_{0}(s) \\
& \left\{\left(m s^{2}+c s+k\right)+k_{m}^{\prime} h b\left[1-e^{-T s}\right]\right\} q(s) \\
& \quad=k_{m}^{\prime} h b a_{0}(s),
\end{aligned}
$$

where $q(s)$ is input and $a_{0}(s)$ is the output of the dynamic grinding process transfer function:

$$
\frac{q(s)}{a_{0}(s)}=\frac{k_{m}^{\prime} h b}{\left(m s^{2}+c s+k\right)+k_{m}^{\prime} h b\left(1-e^{-T s}\right)} .
$$

Let

$$
\begin{aligned}
& W(s)=\frac{1}{m s^{2}+c s+k} \\
& \frac{q(s)}{a_{0}(s)}=\frac{k_{m}^{\prime} h b W(s)}{1+k_{m}^{\prime} h b\left(1-e^{-T s}\right) W(s)} .
\end{aligned}
$$

To let the divisor be zero, the crankshaft (or wheel) system for the characteristic equation of regenerative chatter is

$$
1+k_{m}^{\prime} h b\left(1-e^{-T s}\right) W(s)=0 .
$$

According to the first discrimination method of stable Lyapunov system, $s=\sigma+i \omega$; the system is in the critical state of stability when $\sigma$ is 0 :

$$
W(i \omega)=\frac{-1}{k_{m}^{\prime} h b\left(1-e^{-i \omega T}\right)} .
$$

According to Euler equation, $e^{-i \omega T}=\cos (\omega T)-i \sin (\omega T)$ will be substituted into the above equation:

$$
W(i \omega)=\frac{-1}{k_{m}^{\prime} h b}\left\{\frac{1}{2}+\frac{-i \sin (\omega t)}{2[1-\cos (\omega t)]}\right\} .
$$
sion:

After rearranging (18), we obtain the following expres-

$$
\begin{aligned}
W(s) & =\frac{1}{m\left(s^{2}+(c / m) s+k / m\right)} \\
\omega_{n}^{2} & =\frac{k}{m} \\
\xi & =\frac{-c}{2 m \omega_{n}} \\
\lambda & =\frac{\omega}{\omega_{n}} ;
\end{aligned}
$$

$s=i \omega$ will be substituted into (23):

$$
\begin{aligned}
& W(s)=\frac{1}{m\left(s^{2}+(c / m) s+k / m\right)} \\
& =\frac{1}{m \omega_{n}^{2}}\left[\frac{1-\lambda^{2}}{\left(1-\lambda^{2}\right)+(2 \xi \lambda)^{2}}-i \frac{2 \xi \lambda}{\left(1-\lambda^{2}\right)+(2 \xi \lambda)^{2}}\right] .
\end{aligned}
$$

The real part of (21) and (27) is equal to

$$
\begin{aligned}
\frac{-1}{2 k_{m}^{\prime} h b} & =\frac{1-\lambda^{2}}{m \omega_{n}{ }^{2}\left[\left(1-\lambda^{2}\right)+(2 \xi \lambda)^{2}\right]} \\
h & =\frac{-m \omega_{n}{ }^{2}\left[\left(1-\lambda^{2}\right)+(2 \xi \lambda)^{2}\right]}{2 k_{m}^{\prime} b\left(1-\lambda^{2}\right)} .
\end{aligned}
$$

To make (29) for a partial derivative of $\lambda$, then let the result approach zero:

$$
\lambda=\sqrt{1 \pm 2 \xi}
$$


Bring (30) into (29); then we get the critical grinding depth:

$$
h_{\text {critical }}=\frac{2 k \xi(1+\xi)}{k_{m}^{\prime} b} .
$$

It is shown that the presented approach can be used to predict the crankshaft grinding stability $[5,13]$.

The grinding wheel is easily worn and the regenerative chatter of both workpiece and grinding wheel should be considered.

Critical grinding depth of the crankshaft:

$$
h_{\text {critical-q }}=\frac{2 k_{q} \xi_{q}\left(1+\xi_{q}\right)}{k_{m q}^{\prime} b} .
$$

Critical depth of the grinding wheel wear:

$$
h_{\text {critical-s }}=\frac{2 k_{s} \xi_{s}\left(1+\xi_{s}\right)}{k_{m s}^{\prime} b} \text {. }
$$

\section{Experimental Study}

The complicated phenomena in engineering cannot be concluded only by theoretical analysis and the accuracy of theoretical analysis results need be verified by experiment.

\subsection{The Test Experiment of Crankshaft Circumferential Stiff-} ness Change. As the crankshaft is an elongate and complex shape shaft, the crankpin deforms during the grinding process. The center frame is generally used in the machining of crankshaft to eliminate the influence of the gravity, so the grinding force is the main cause of crankpin deformation.

In order to further study the influence of grinding force on the deformation of crankpin, we take the crankshaft of D06A-101-30 diesel engine as the experimental object. The number 1 crankpin was applied to the $200 \mathrm{~N}$ vertical constant force to simulate the idea that the crankshaft was stressed by the normal grinding force of $200 \mathrm{~N}$. In the experiment, two laser displacement sensors were used to measure the deformation of crankpin in two directions, as shown in Figure 6.

First, the crankshaft is rotated without the weight, and the position of the crankpin is measured at 5 degrees from the angle of crankpin which is 0 degrees. Then, under the weight of $200 \mathrm{~N}$, repeat the above measurement procedure and another group of position dates is obtained. The difference between the two groups is the deformation in the radius direction of crankpin under the grinding force $200 \mathrm{~N}$. Finally we can achieve the deformation and stiffness of crankpin as in Table 1 and Figure 7:

$$
K=\frac{P}{\Delta R}
$$

where $K$ and $P$ represent stiffness of crankpin and grinding force, respectively. $\Delta R$ denotes the deformation in the radius direction of crankpin.

According to the experimental results and the structural characteristics of the crankshaft, we use cosine curve fitting its

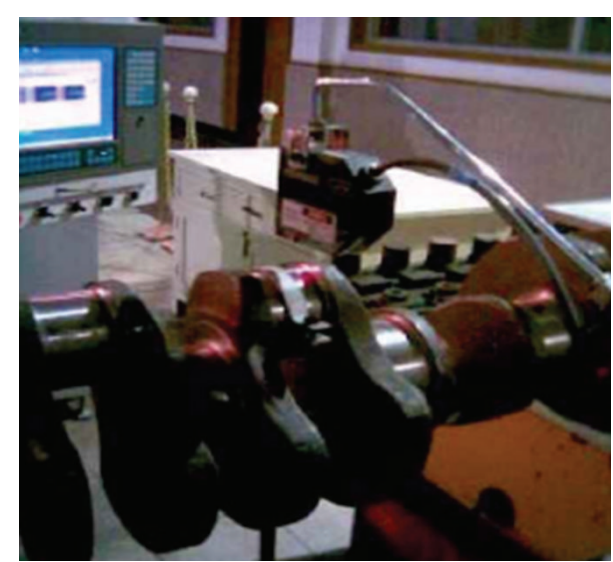

Figure 6: The test experiment of crankshaft circumferential stiffness.



Figure 7: Crankpin Stiffness of the experiment.

stiffness, as shown in Figure 8. We can obtain the expression of the stiffness of the crankshaft.

If we plug the parameters of Table 2 into the above formulas, we can obtain the stability lobe diagram shown in Figure 9.

In the diagram, above the lobe line is "The unstable region" of the grinding system and below the lobe line is "The stability region."

The crankshaft is a complex shape shaft and its circumferential stiffness is different $[14,15]$. In the diagram, it is shown that accounting for the uncertainty or variability of the process parameters can influence the stability boundary and the fuzzy stable region has been formed [16].

As the grinding wheel speed increasing, the limit grinding depth also has the tendency of increase. Therefore, by increasing the grinding wheel speed and keeping the grinding depth less than the critical depth, we can make the process in a stable state and the processing efficiency is improved. 
TABLE 1: The deformation and stiffness of crankpin.

\begin{tabular}{|c|c|c|}
\hline $\begin{array}{l}\text { The angle of crankpin } \\
\left({ }^{\circ}\right)\end{array}$ & $\begin{array}{l}\text { The deformation } \\
(\mathrm{mm})\end{array}$ & $\begin{array}{c}\text { Stiffness of crankpin } \\
(\mathrm{N} / \mathrm{mm})\end{array}$ \\
\hline 0 & 0.0213 & 9389.671 \\
\hline 5 & 0.0214 & 9375.934 \\
\hline 10 & 0.0213 & 9389.671 \\
\hline 15 & 0.0217 & 9216.590 \\
\hline 20 & 0.0218 & 9174.312 \\
\hline 25 & 0.0219 & 9132.420 \\
\hline 30 & 0.0218 & 9174.312 \\
\hline 35 & 0.0221 & 9049.774 \\
\hline 40 & 0.0228 & 8771.930 \\
\hline 45 & 0.0229 & 8733.624 \\
\hline 50 & 0.0232 & 8620.690 \\
\hline 55 & 0.0243 & 8230.453 \\
\hline 60 & 0.0240 & 8333.333 \\
\hline 65 & 0.0252 & 7936.508 \\
\hline 70 & 0.0259 & 7722.008 \\
\hline 75 & 0.0256 & 7812.500 \\
\hline 80 & 0.0260 & 7692.308 \\
\hline 85 & 0.0259 & 7722.008 \\
\hline 90 & 0.0261 & 7662.835 \\
\hline 95 & 0.0253 & 7905.138 \\
\hline 100 & 0.0257 & 7782.101 \\
\hline 105 & 0.0255 & 7843.137 \\
\hline 110 & 0.0247 & 8097.166 \\
\hline 115 & 0.0237 & 8438.819 \\
\hline 120 & 0.0234 & 8547.009 \\
\hline 125 & 0.0237 & 8438.819 \\
\hline 130 & 0.0237 & 8438.819 \\
\hline 135 & 0.0228 & 8771.930 \\
\hline 140 & 0.0228 & 8771.930 \\
\hline 145 & 0.0220 & 9090.909 \\
\hline 150 & 0.0216 & 9259.259 \\
\hline 155 & 0.0213 & 9389.671 \\
\hline 160 & 0.0214 & 9375.934 \\
\hline 165 & 0.0212 & 9433.962 \\
\hline 170 & 0.0215 & 9302.326 \\
\hline 175 & 0.0214 & 9375.934 \\
\hline 180 & 0.0218 & 9174.312 \\
\hline 185 & 0.0225 & 8888.889 \\
\hline 190 & 0.0226 & 8849.558 \\
\hline 195 & 0.0223 & 8968.610 \\
\hline 200 & 0.0225 & 8888.889 \\
\hline 205 & 0.0226 & 8849.558 \\
\hline 210 & 0.0224 & 8928.571 \\
\hline 215 & 0.0230 & 8695.652 \\
\hline 220 & 0.0227 & 8810.573 \\
\hline 225 & 0.0237 & 8438.819 \\
\hline
\end{tabular}

TABLE 1: Continued.

\begin{tabular}{|c|c|c|}
\hline $\begin{array}{l}\text { The angle of crankpin } \\
\left({ }^{\circ}\right)\end{array}$ & $\begin{array}{l}\text { The deformation } \\
(\mathrm{mm})\end{array}$ & $\begin{array}{l}\text { Stiffness of crankpin } \\
(\mathrm{N} / \mathrm{mm})\end{array}$ \\
\hline 230 & 0.0249 & 8032.129 \\
\hline 235 & 0.0250 & 8000.000 \\
\hline 240 & 0.0255 & 7843.137 \\
\hline 245 & 0.0257 & 7782.101 \\
\hline 250 & 0.0255 & 7843.137 \\
\hline 255 & 0.0257 & 7782.101 \\
\hline 260 & 0.0252 & 7936.508 \\
\hline 265 & 0.0260 & 7692.308 \\
\hline 270 & 0.0254 & 7874.016 \\
\hline 275 & 0.0268 & 7462.687 \\
\hline 280 & 0.0270 & 7407.407 \\
\hline 285 & 0.0270 & 7407.407 \\
\hline 290 & 0.0268 & 7462.687 \\
\hline 295 & 0.0270 & 7407.407 \\
\hline 300 & 0.0268 & 7462.687 \\
\hline 305 & 0.0263 & 7604.563 \\
\hline 310 & 0.0250 & 8000.000 \\
\hline 315 & 0.0241 & 8298.755 \\
\hline 320 & 0.0241 & 8298.755 \\
\hline 325 & 0.0228 & 8771.930 \\
\hline 330 & 0.0231 & 8658.009 \\
\hline 335 & 0.0218 & 9174.312 \\
\hline 340 & 0.0218 & 9174.312 \\
\hline 345 & 0.0213 & 9389.671 \\
\hline 350 & 0.0215 & 9302.326 \\
\hline 355 & 0.0210 & 9523.810 \\
\hline 360 & 0.0213 & 9389.671 \\
\hline
\end{tabular}

TABLE 2: The parameter of the grinding process.

\begin{tabular}{lcccc}
\hline$k_{m}^{\prime}\left(\mathrm{N} / \mathrm{mm}^{2}\right)$ & $k(\mathrm{~N} / \mathrm{mm})$ & $\xi$ & $\omega(\mathrm{rad} / \mathrm{s})$ & $b(\mathrm{~mm})$ \\
\hline 1025 & $\begin{array}{c}(8.503903+\cos \theta) \\
* 1000\end{array}$ & 0.053 & 439.82 & 30 \\
\hline
\end{tabular}

5.2. Experimental Results Contrast. In order to verify the correctness of the stability limit diagram, we carried out the relevant grinding experiments [17-19]. The specific parameters of the workpiece and grinding wheel are shown in Table 3.

We apply Bruel \& Kjaer 4366 accelerometer to the grinding machine in order to detect chatter vibrations. The sensor was mounted on the tailstock center (Figure 11). In the process of grinding, the acceleration amplitude of regenerative chatter is increased rapidly with the grinding time. Figures 12 and 13 display the normal and the chatter signals.

Crankshaft Tangential Point Tracing grinding setup is shown in Figure 10. Each test was measured more than three times during grinding, so that the signals produced were sufficient to obtain information. 
TABLE 3: The specific parameters of the workpiece and grinding wheel.

\begin{tabular}{lcc}
\hline $\begin{array}{l}\text { Name of the } \\
\text { workpiece }\end{array}$ & $\begin{array}{c}\text { Material of the } \\
\text { workpiece }\end{array}$ & $\begin{array}{c}\text { Type of grinding } \\
\text { wheel }\end{array}$ \\
\hline $\begin{array}{l}\text { Diesel engine } \\
\text { crankshaft }\end{array}$ & CK45 & $\begin{array}{c}\text { AWA(19A)- } \\
\text { white corundum } \\
\text { mixed abrasive }\end{array}$ \\
\hline
\end{tabular}

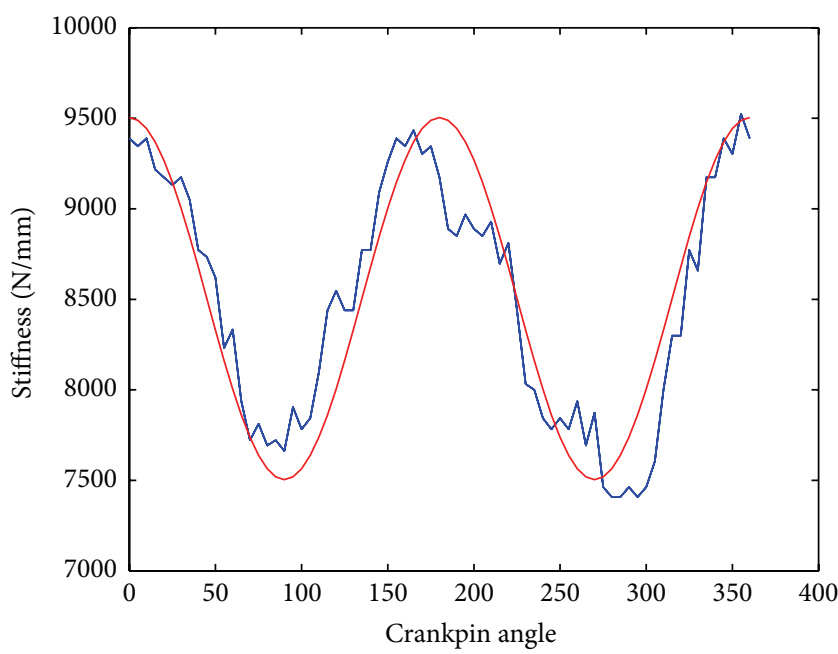

FIGURE 8: Crankpin Stiffness of the experiment and fitting curve.

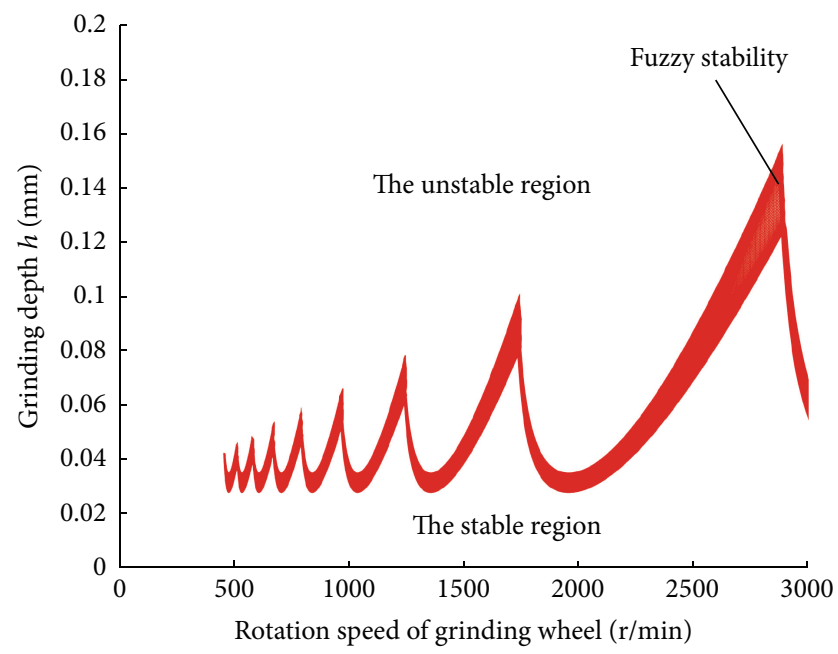

Figure 9: Stability lobe diagram.

The crankshaft rotation speed is set to $6 \mathrm{r} / \mathrm{min}$ and the speed of the grinding wheel is $1250 \mathrm{r} / \mathrm{min}, 1450 \mathrm{r} / \mathrm{min}$, and $1650 \mathrm{r} / \mathrm{min}$ in grinding experiment. In the case of certain rotational speed, the boundary value of the chatter is determined continuously by changing the depth of the grinding. The chatter points are basically over the stability limit of the curve or near and so the experimental results are consistent with the predictions of the stability limit diagram. Therefore, it is proved that the prediction method is effective and reliable.

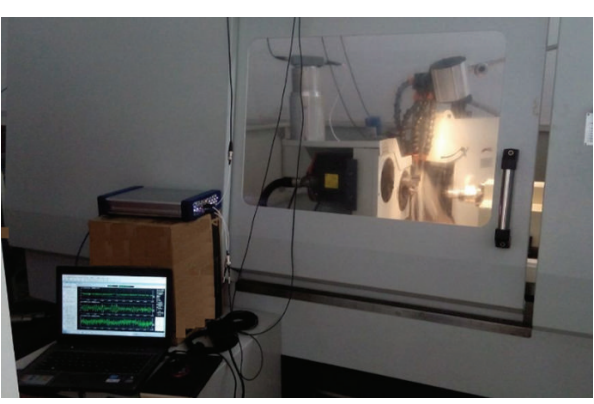

FIGURE 10: Experiment setup.

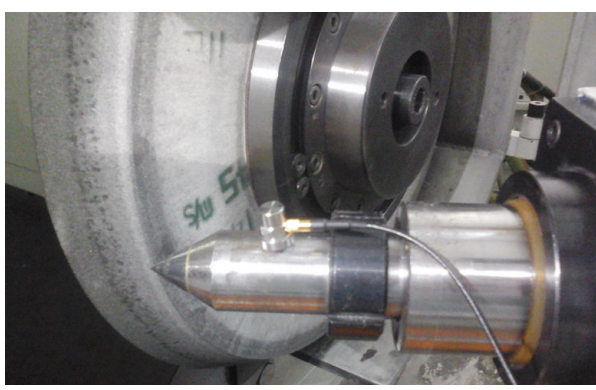

FIgURE 11: The position of acceleration sensors.

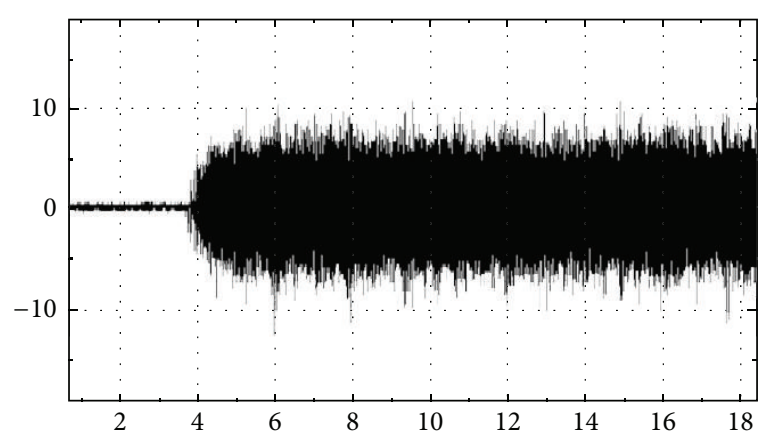

(s)

Figure 12: The normal signals.

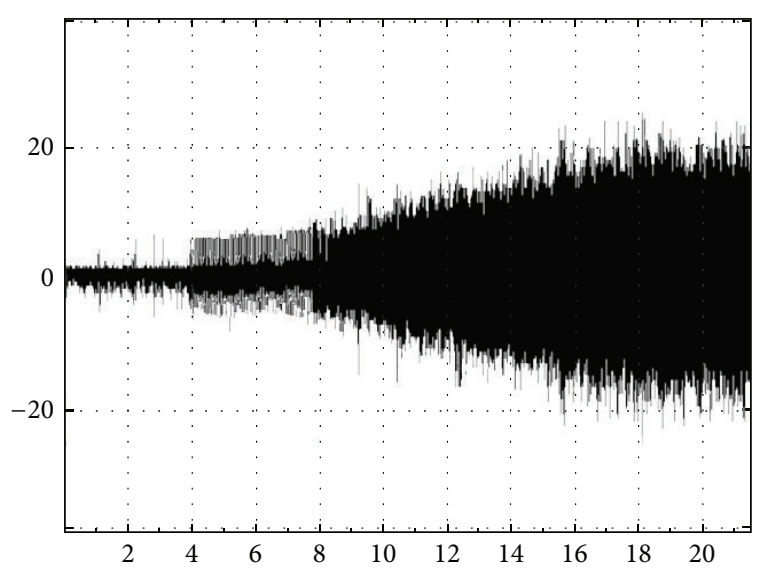

(s)

FIGURE 13: The chatter signals. 


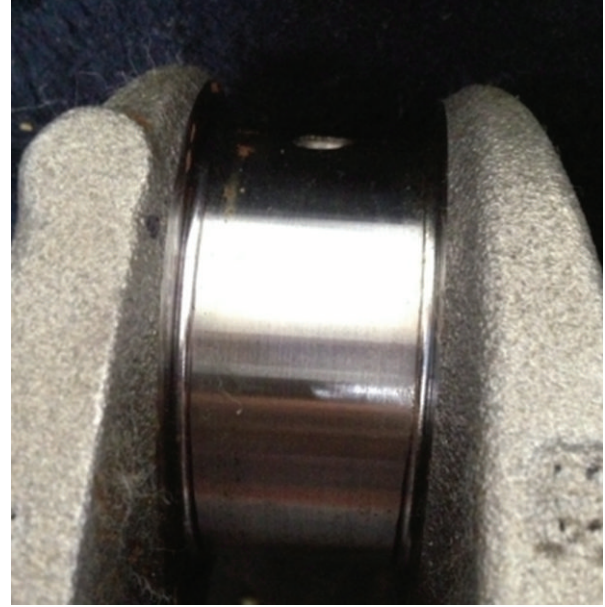

(a) Vibration Waviness of crankpin

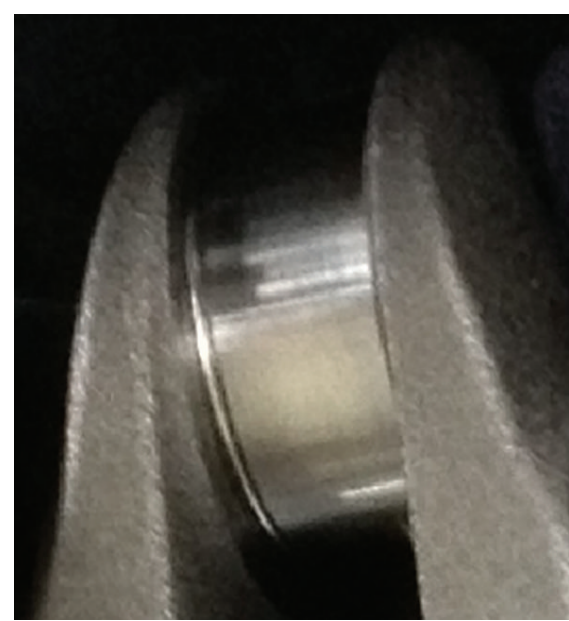

(b) Vibration Waviness of crankpin

FIGURE 14: Crankpin surface after chatter in grinding.

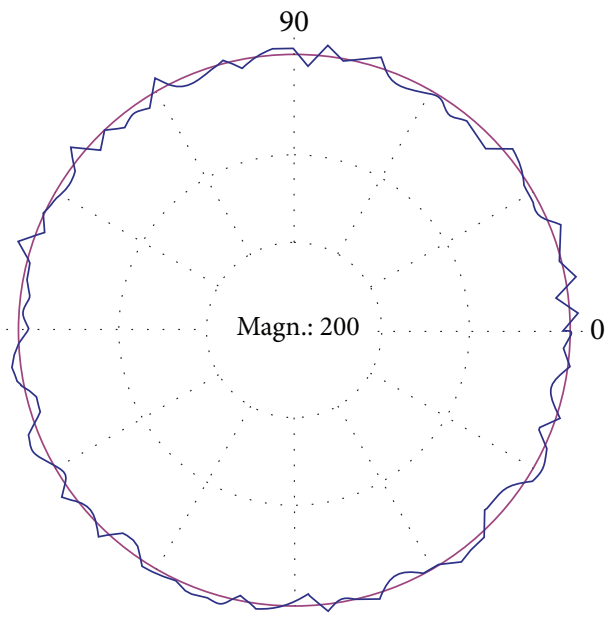

(a) The normal

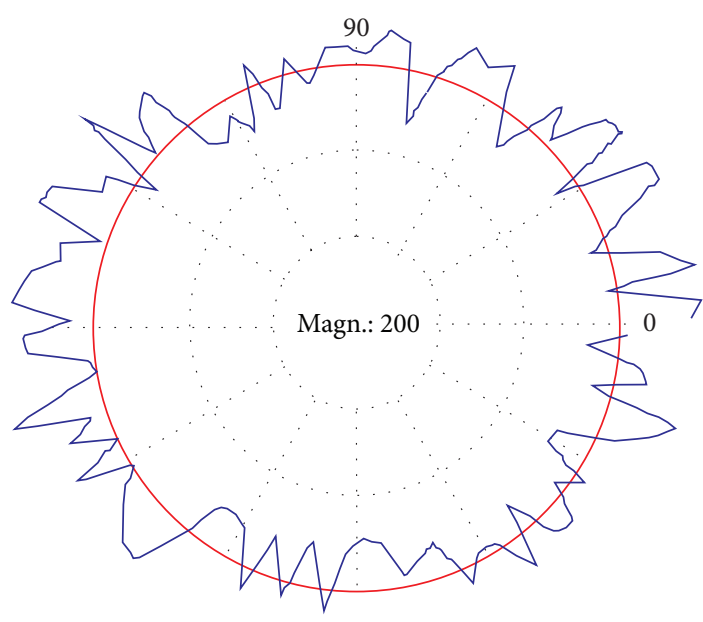

(b) The grinding chatter

FIGURE 15: The crankpin profile.

We can see chatter marks (Vibration Waviness) with naked eye on the crankpin surface as in Figure 14. Roundness measurement results show that the instability of the regenerative chatter caused by the instability of the grinding phenomenon makes the roundness of the workpiece poor, as shown in Figure 15.

\section{Conclusions}

To study how to avoid chatter in crankshaft Tangential Point Tracing grinding, Stability lobe diagram has been developed based on dynamic model to predict chatter and some conclusions have been drawn as follows:

(1) The dynamic equation of the grinding system has been constructed by the dynamic analysis of the grinding system.
(2) Expression of the critical crankshaft grinding depth has been developed based upon the work of Altintaş and Budak [5] and Stepan [13].

(3) Through the experimental study, the law of crankshaft rigidity is obtained.

(4) The stability of the grinding system can be predicted by using the method of drawing the stability diagram.

(5) Experimental results show that the prediction method is consistent with the experimental data.

\section{Nomenclature}

$k_{1}$ and $k_{4}$ : Equivalent stiffness of the support system of $X$ and $Y$ direction in generalized coordinates in the time of the grinding of the crankpin, respectively 
$k_{1}^{\prime}$ and $k_{4}^{\prime}$ : Equivalent stiffness of the right support system of $X$ and $Y$ direction in generalized coordinates in the time of the grinding of the crankpin, respectively

$k_{1}^{\prime \prime}$ and $k_{4}^{\prime \prime}$ : Equivalent stiffness of the left support system of $X$ and $Y$ direction in generalized coordinates in the time of the grinding of the crankpin, respectively: $k_{1}=k_{1}^{\prime}+$ $k_{1}^{\prime \prime} ; k_{4}=k_{4}^{\prime}+k_{4}^{\prime \prime}$

$c_{1}$ and $c_{4}$ : Equivalent damping of the support system of $X$ and $Y$ direction in generalized coordinates in the time of the grinding of the crankpin, respectively

$c_{1}^{\prime}$ and $c_{4}^{\prime}$ : Equivalent damping of the right support system of $X$ and $Y$ direction in generalized coordinates in the time of the grinding of the crankpin, respectively

$c_{1}^{\prime \prime}$ and $c_{4}^{\prime \prime}$ : Equivalent damping of the left support system of $X$ and $Y$ direction in generalized coordinates in the time of the grinding of the crankpin, respectively: $c_{1}=c_{1}^{\prime}+c_{1}^{\prime \prime} ; c_{4}=$ $c_{4}^{\prime}+c_{4}^{\prime \prime}$

$k_{c}$ : $\quad$ Contact stiffness of crankshaft and grinding wheel

$k_{g}$ : $\quad$ Grinding rigidity of crankshaft and grinding wheel

$k_{a}$ : $\quad$ Normal grinding stiffness of crankshaft and grinding wheel

$k_{2}$ : The grinding stiffness and contact stiffness's equivalent stiffness of the crankshaft and the grinding wheel: $k_{2}=k_{c} k_{g} /\left(k_{c}+k_{g}\right)$

$k_{3}$ : $\quad$ Equivalent support stiffness of the grinding wheel system in the $X$ direction of the generalized coordinates

$c_{3}: \quad$ The equivalent damping of the grinding wheel system in the $X$ direction of the generalized coordinate system

$m_{1}: \quad$ Masses of the crankshaft

$m_{2}: \quad$ Masses of the grinding wheel

$k_{5}$ : $\quad$ Equivalent stiffness of the support system of the grinding wheel of $Y$ direction in generalized coordinates

$c_{5}$ : $\quad$ Equivalent damping of the support system of the grinding wheel of $Y$ direction in generalized coordinates

$Q_{1}$ : The force of the grinding system in the direction of $X$ of the generalized system

$Q_{2}$ : The force of the grinding system in the direction of $Y$ of the generalized system

$q_{1}$ and $q_{2}$ : The displacement of the crankshaft horizontal and vertical direction shift

$q_{3}$ : The displacement of wheel horizontal direction shift

$\alpha: \quad$ The rotation angle of crankpin

$\beta: \quad$ The angle between $\overline{\mathrm{O}_{S} \mathrm{O}_{W}}$ and $\overline{\mathrm{OO}_{S}}$ (Figure 3)

$R: \quad$ The eccentric distance of the crankpin

$R_{s}: \quad$ The radius of the grinding wheel

$\begin{array}{ll}R_{w}: & \text { The radius of the crankpin } \\ F_{n}: & \text { The normal grinding force } \\ F_{t}: & \text { The tangential grinding force } \\ M: & \text { The additional couple } \\ \zeta: & \text { The friction coefficient between the con- } \\ & \text { tact surface of the grinding wheel and } \\ & \text { the crankpin } \\ F(t): & \text { The dynamic grinding force } \\ t: & \text { The time } \\ h_{g}: & \text { The grinding depth of the workpiece } \\ h_{w}: & \text { The grinding depth of the wheel } \\ h_{g} \text { and } h_{w}: \text { The opposite of its direction, assuming } & \text { the grinding depth of the workpiece is a } \\ & \text { positive direction } \\ k_{m}^{\prime}: & \text { The grinding force coefficient of work- } \\ h: & \text { piece (or grinding wheel) } \\ & \text { The grinding depth of workpiece (or } \\ b: & \text { grinding wheel) } \\ a_{0}(t): & \text { The grinding contact width } \\ & \text { The vibration pattern of the surface of } \\ T: & \text { the workpiece (or wheel) for the moment } \\ \omega_{n}: & \text { The rotation period of workpiece (or } \\ \xi: & \text { wheel) }\end{array}$

\section{Conflict of Interests}

The authors declare that there is no conflict of interests regarding the publication of this paper.

\section{Acknowledgments}

This work is supported by National Science and Technology Major Project of China under Grant no. 2009ZX04001-111. It is also supported by Key Scientific Research Projects of Jiujiang University under Grant no. 2013ZD08. The authors are grateful for the financial support and also would like to thank the anonymous reviewers and the editor for their comments and suggestions.

\section{References}

[1] A. Walsh, Mathematical modelling of the crankshaft pin grinding process [Ph.D. thesis], Deakin University, Victoria, Australia, 2004.

[2] T. Fujiwara, S. Tsukamoto, and M. Miyagawa, "Analysis of the grinding mechanism with wheel head oscillating type CNC crankshaft pin grinder," Key Engineering Materials, vol. 291-292, pp. 163-168, 2005.

[3] M. Hitchiner and J. Webster, "Recent advaiuces in amshaft and crankshaft grinding," Abrasives Magazine, pp. 7-12, 2001.

[4] J. Tlusty and M. Polacek, "The stability of machine tool against self excited vibrations in machining," in Proceedings of the ASME Production Engineering Research Conference, pp. 465474, Pittsburgh, Pa, USA, 1963. 
[5] Y. Altintaş and E. Budak, "Analytical prediction of stability lobes in milling," CIRP Annals-Manufacturing Technology, vol. 44, no. 1, pp. 357-362, 1995.

[6] I. Inasaki, B. Karpuschewski, and H.-S. Lee, "Grinding chatterorigin and suppression," CIRP Annals-Manufacturing Technology, vol. 50, no. 2, pp. 515-534, 2001.

[7] G. Quintana, J. Ciurana, and D. Teixidor, "A new experimental methodology for identification of stability lobes diagram in milling operations," International Journal of Machine Tools and Manufacture, vol. 48, no. 15, pp. 1637-1645, 2008.

[8] K.-C. Cha, N.-Z. Wang, and J.-Y. Liao, "Dynamics and stability analysis of the simplified model for the surface grinder in various worktable positions," Proceedings of the Institution of Mechanical Engineers Part K: Journal of Multi-Body Dynamics, vol. 225, no. 3, pp. 220-234, 2011.

[9] R. Drazumeric, J. Badger, and P. Krajnik, "Geometric, kinematical and thermal analyses of non-round cylindrical grinding," Journal of Materials Processing Technology, vol. 214, no. 4, pp. 818-827, 2014.

[10] Q. Song, X. Ai, and W. Tang, "Prediction of simultaneous dynamic stability limit of time-variable parameters system in thin-walled workpiece high-speed milling processes," International Journal of Advanced Manufacturing Technology, vol. 55, no. 9-12, pp. 883-889, 2011.

[11] T. L. Schmitz and K. S. Smith, Machining Dynamics: Frequency Response to Improved Productivity, Springer, New York, NY, USA, 2009.

[12] L. Yuan, V.-M. Järvenpää, E. Keskinen, and M. Cotsaftis, “Simulation of roll grinding system dynamics with rotor equations and speed control," Communications in Nonlinear Science and Numerical Simulation, vol. 7, no. 3, pp. 95-106, 2002.

[13] G. Stepan, "Modelling non-linear regenerative effects in metal cutting," Philosophical Transactions of the Royal Society, vol. 359, no. 1781, pp. 739-757, 2001.

[14] Z. Zhou, H. Luo, D. Xu, Z. Sun, and H. Mi, "Analysis and compensation of stiffness-error of crankshaft in tangential point tracing grinding," Chinese Journal of Mechanical Engineering, vol. 39, no. 6, pp. 98-101, 2003 (Chinese).

[15] G. Wu, Research on the key technique on noncircular crankshaft grinding [Ph.D. thesis], Shanghai University, Shanghai, China, 2011 (Chinese).

[16] N. D. Sims, G. Manson, and B. P. Mann, "Fuzzy stability analysis of regenerative chatter in milling," Journal of Sound and Vibration, vol. 329, no. 8, pp. 1025-1041, 2010.

[17] C. F. Yao, Q. C. Jin, X. C. Huang, D. X. Wu, J. X. Ren, and D. H. Zhang, "Research on surface integrity of grinding Inconel718," International Journal of Advanced Manufacturing Technology, vol. 65, no. 5-8, pp. 1019-1030, 2013.

[18] K. Wegener, H.-W. Hoffmeister, B. Karpuschewski, F. Kuster, W.-C. Hahmann, and M. Rabiey, "Conditioning and monitoring of grinding wheels," CIRP Annals-Manufacturing Technology, vol. 60, no. 2, pp. 757-777, 2011.

[19] G. Tlusty, Manufacturing Processes and Equipment, Prentice Hall, Upper Saddle River, NJ, USA, 2000. 


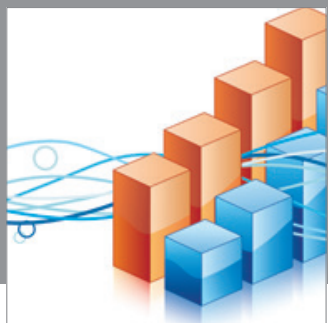

Advances in

Operations Research

mansans

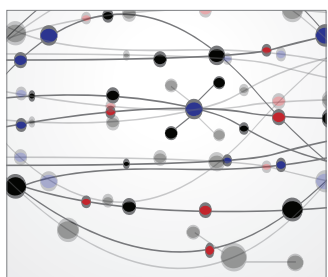

The Scientific World Journal
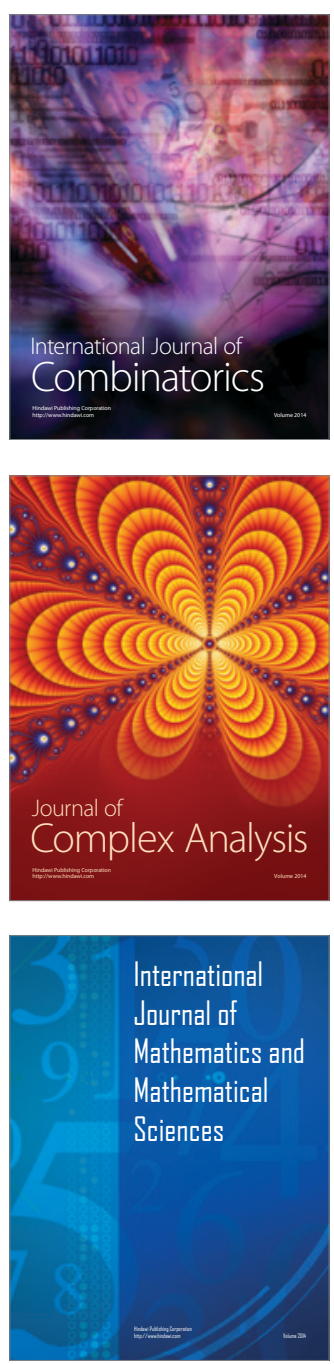
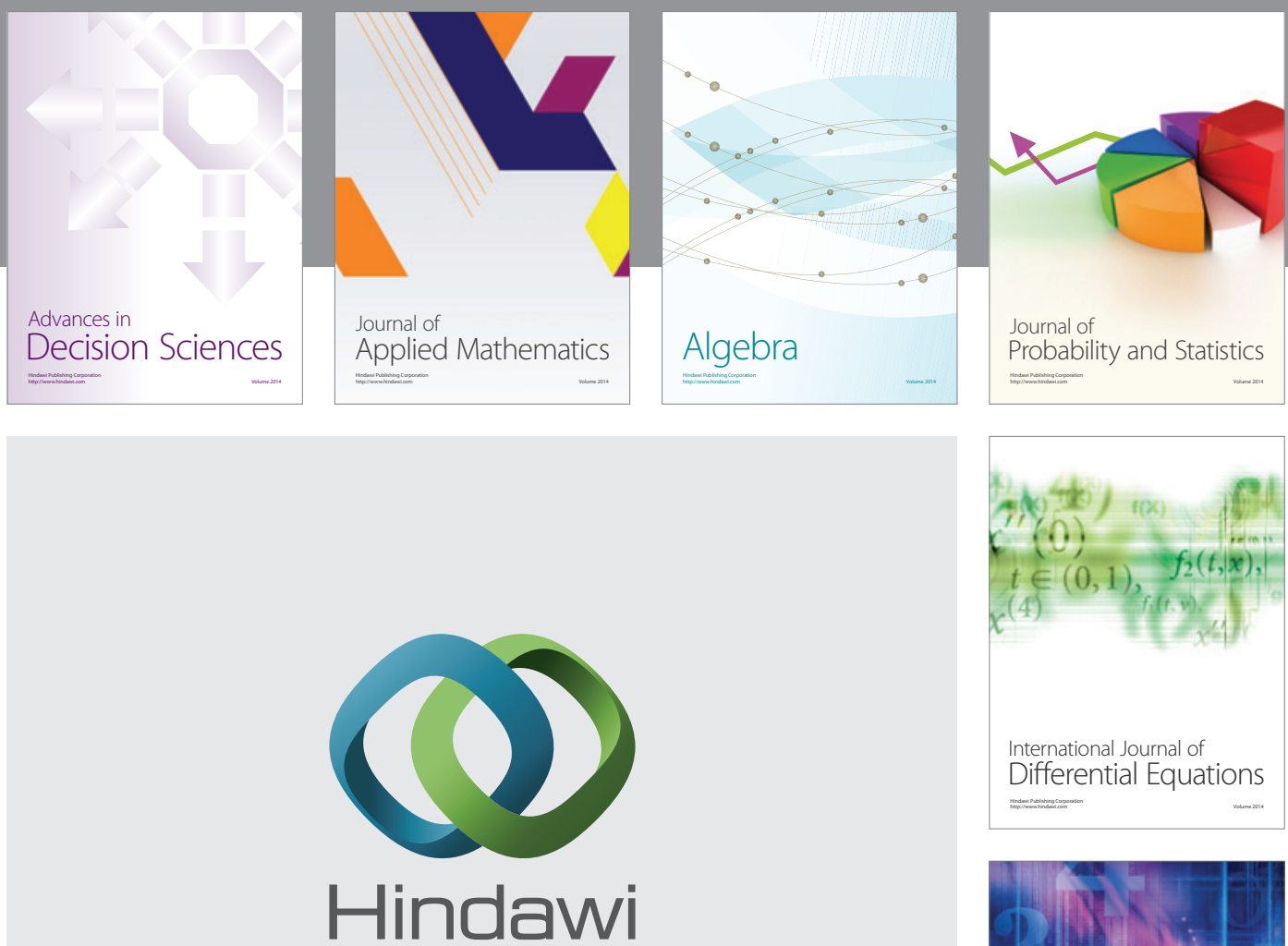

Submit your manuscripts at http://www.hindawi.com
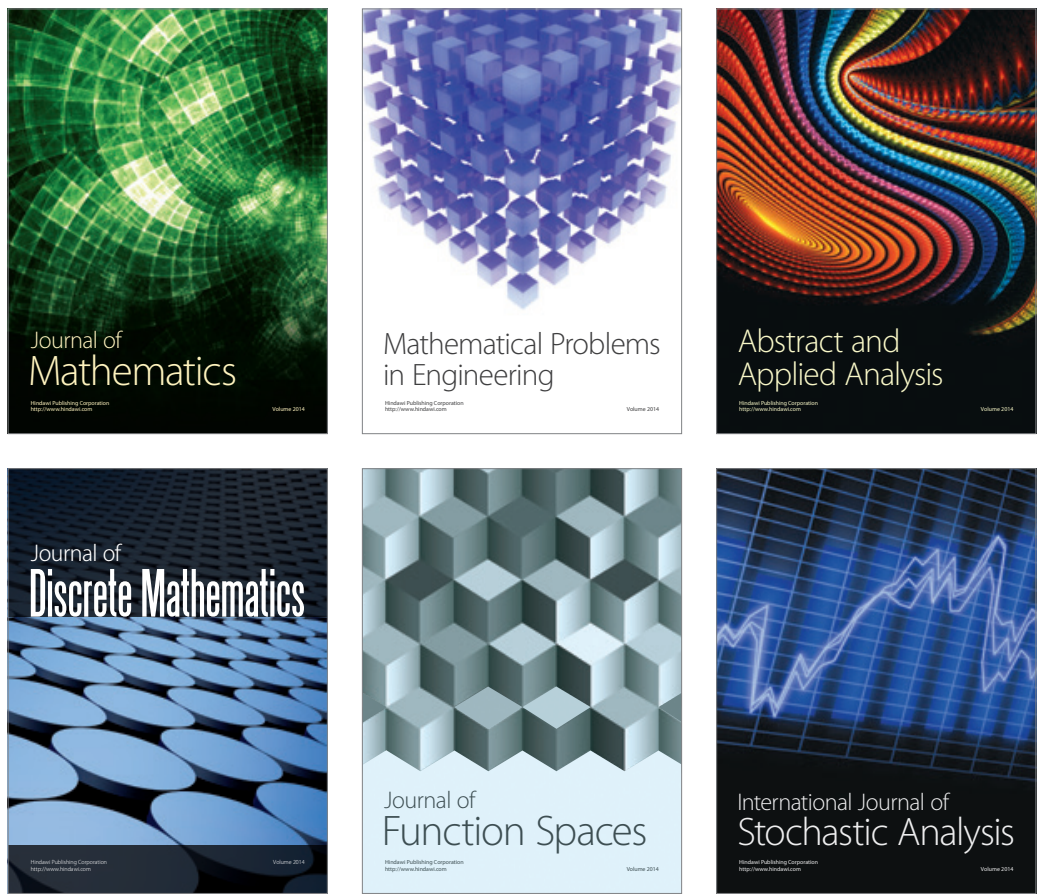

Journal of

Function Spaces

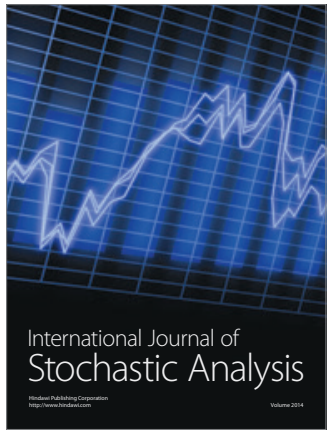

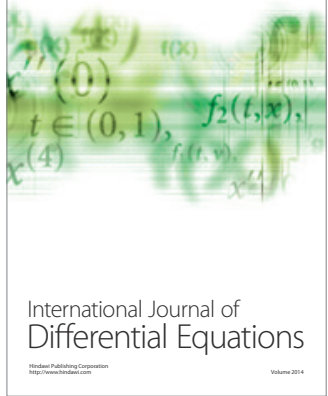
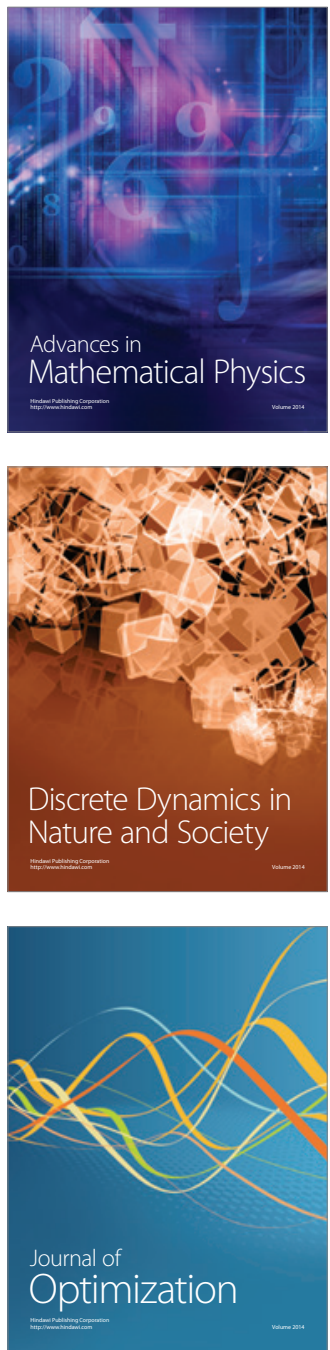